\title{
EDITORIAL
}

\section{To a new chapter}

\section{T. W. L. Scheeren ${ }^{1}$}

Accepted: 8 January 2021 / Published online: 28 January 2021

(c) The Author(s), under exclusive licence to Springer Nature B.V. part of Springer Nature 2021

"If you do not change direction, you may end up where you are heading"

Lao Tzu, sixth century BC

A new chapter has begun for the Journal of Clinical Monitoring and Computing on January $1^{\text {st }}, 2021$ with the transition of the Editor-in-Chief (EiC) position from Professor Steven Rees, who concludes his term after nine successful years, to me, Professor Thomas Scheeren.

Taking the role of Professor Steven Rees as EiC will be a challenging task, since he was most successful in developing the Journal from a Q4 publication without an ISI impact factor (IF) to a unique, well-established and appreciated member of the top journals' family in the clinical fields of anesthesia, intensive care and perioperative medicine over the nine years of his leadership. Thanks to his efforts and as a reflection of the increased Journal's quality, the number of submissions steadily increased by about $20 \%$ each year (to 597 submission in 2020), and the IF has stabilized at a satisfactory level for a niche journal (Fig. 1). In general, although getting much attention in the academic world, the relevance of a journal's IF should not be overrated as it poorly reflects the quality of individual researchers or journals. According to traditional bibliometrics and key performance indicators, the papers published in the Journal are manyfold downloaded (around 205,000 downloads in 2020), read and cited throughout the world, increasingly mentioned in Altmetrics, and find attention in the social media (total social media mentions almost tripled in the past three years from 221 to 619 ).

Prof. Rees also started the process of renewing and expanding the Editorial Board of the Journal by appointing new Associate Editors, among which me [1]. This process will now be continued by the appointment of four new Associate Editors, these being Professors Henrik Holm-Sørensen

T. W. L. Scheeren

t.w.1.scheeren@umcg.nl

1 Department of Anesthesiology, University Medical Center Groningen, University of Groningen, Hanzeplein 1, 9700 Groningen, RB, The Netherlands from Copenhagen, Denmark, Alexandre Joosten from Paris, France, Dan Stieper Karbing from Aalborg, Denmark, and Simon Tilma Vistisen from Aarhus, Denmark. Together with the existing Associate Editors, Professors Jan Hendrickx and Tom van Zundert (both Aalst, Belgium), Bernd Saugel (Hamburg, Germany) and Stanley Skinner (Minneapolis, USA) we have a powerful team of talented experts (clinicians as well as biomedical engineers) covering the topics ranging from hemodynamic and respiratory monitoring and cardiovascular therapy, neurophysiological and tissue oxygenation monitoring, anesthesia and airway management, to newer subjects such as artificial intelligence, big data and machine learning, and monitoring of the microcirculation.

New challenges are waiting for us to be solved, e.g. open access publishing, the necessity to continue having a paper print journal versus going fully electronic, the dissemination of the published research on social media, journal selfcitations policies, gender diversity among authors, reviewers and Editorial Board members (see below), the (quality and usefulness of the) peer reviewing process, and offering preprint sharing services, just to name a few. Furthermore, the research focus of our Journal should encourage us to stimulate the production of standards and consensus statements on how to conduct and report such research, thereby improving its quality.

Looking at this honorable lineup of Associate Editors, the reader may notice an only male team, not fulfilling any diversity criteria. The ugly truth is that the topics covered by a technological journal like ours (dealing mainly with "toys for boys") are apparently not attracting women that much so far. Anyway, I am looking forward to welcoming (proposals for) the first female Associate Editor at the Journal hopefully soon!

I will try to continue the most successful work of Professor Steven Rees in my new role as incoming EiC and contribute to a hopefully bright future of the Journal. This cannot be achieved without the continuous support of you, the readers, authors, reviewers, editorial board members, Associate Editors and members of the production team of the Journal of Clinical Monitoring and Computing! Last but not least I want to thank Steve (Rees) personally for all his 


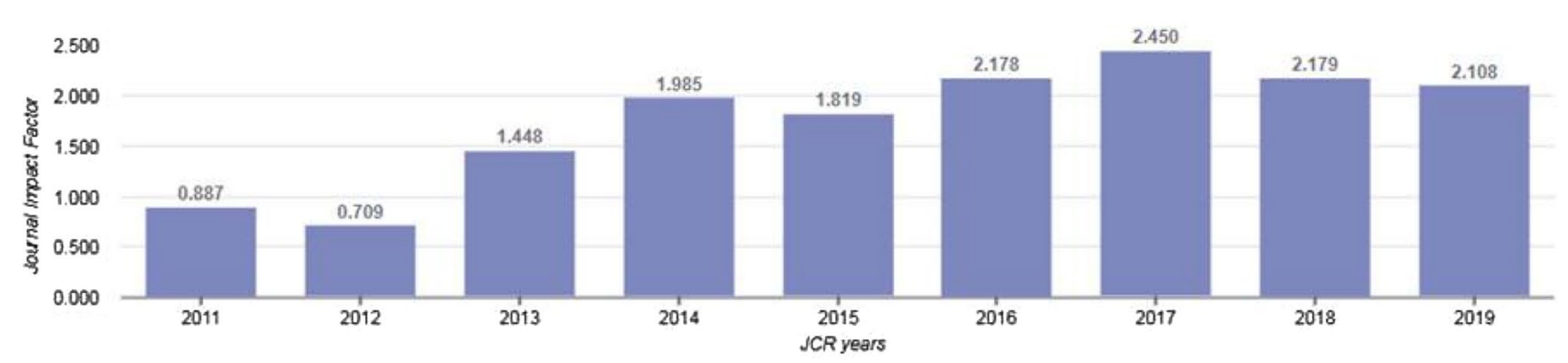

Fig. 1 Development of the journal impact factor of the Journal of Clinical Monitoring and Computing (JCMC) from 2011 to 2019

support and guidance throughout the years: it was a pleasure and honor working with you, and I wish you all the best and success with your new ideas and future initiatives!
Publisher's Note Springer Nature remains neutral with regard to jurisdictional claims in published maps and institutional affiliations.

\section{Reference}

1. Rees SE. New times at the Journal of Clinical Monitoring and Computing. J ClinMonitComput. 2015;29(4):427. 